\title{
4
}

\section{A Learner-Centred Mock Conference Model for Undergraduate Teaching}

Kari Kumar

University of Ontario Institute of Technology

This essay describes a mock conference model of instruction suitable for use in undergraduate teaching, and which adheres to principles of learner-centred instruction and universal design for learning. A staged process of learner preparation for the conference is outlined, and student and instructor roles during preconference, conference, and post-conference periods are described. The model is not discipline-specific or course level-specific and may be utilized in a variety of teaching contexts. I have implemented this model in a first-year undergraduate course, where students presented conference-style oral presentations and virtual poster presentations, and I guided them along the staged preparation process. Potential benefits of this model include fostering the development of self-directed autonomous learners by prompting students to take responsibility for their own learning, and providing students with diverse learning preferences and needs with equal opportunities to succeed by imparting variety and flexibility into the way in which course material is presented.

\section{Introduction}

$\mathrm{L}$ earner-centred teaching approaches shift the emphasis from instructor teaching towards student learning, in contrast to teacher-centred approaches. The value of learner-centred teaching is supported by the literature on learning (Bransford, Brown, \& Cocking, 1999; Candy, 1991; Weimer, 2002) and has been shown to be effective in higher education (Alsardary \& Blumberg, 2009; Kramer et al., 2007; Salinas, Kane-Johnson, \& Vasil-Miller, 2008; Schiller, 2009). Weimer (2002) describes five key changes that can be made to teacher-centred practices towards achieving learner-centred teaching. She suggests a shift in the balance of power, such that power is shared between instructor and student; dual function of content, such that instruction facilitates both learning of content and acquisition of learning skills; the instructor takes on the role of learning guide, and students play a dominant role in the class; students take enhanced responsibility for learning; and a shift in evaluation purpose and processes, such that evalu- 
ation methods promote effective learning processes in addition to generating grades. Interwoven into learner-centred teaching practices is the importance of grooming students to become lifelong learners, by development of self-directed learning skills and active learning practices (Candy, 1991; Weimer, 2002).

Another challenge that we face as educators is to support student diversity in our classrooms (McGlynn, 2007; Orr \& Hammig, 2009; Taylor \& House, 2010; Zeff, 2007). To this end, the Universal Design for Learning (UDL) framework (Rose \& Meyer, 2002), can be applied towards achieving inclusive teaching in higher education (Pliner \& Johnson, 2004; Scott, McGuire, \& Foley, 2003). UDL promotes flexible course design in order to circumvent the need for students to adapt to succeed in our course. The key principles of UDL, as described by Rose \& Meyer (2002), are to incorporate multiple means of representation, expression, and motivation into teaching practices, in order to account for learner differences in receiving and analyzing information, expressing their understanding of concepts and differences in affective learning networks.

This essay describes a mock conference model, an instructional method that is aligned with principles of learner-centred teaching and UDL, and which is adaptable to various teaching contexts. The model is described by providing an overview of student and instructor activities that take place during pre-conference, conference, and postconference periods. Outcomes of implementation of the model are also described and the relevance to learner-centred teaching and UDL is highlighted.

\section{The Mock Conference Model}

I developed the mock conference model for use in a first-year undergraduate course to serve both as an instructional method and a graded assessment, whereby students are evaluated on a conference presentation. Students follow a four stage process in order to prepare and deliver their presentation, as shown in Figure 1.

\section{Preconference activities}

I implemented this model in a class of nursing students, where I set the conference theme of "Mechanisms of Microbial Disease" to provide a forum for the students to culminate their knowledge of course concepts towards a topic that is relevant to nursing practice. Students complete stage one of conference preparation by forming presentation groups, and choosing their presentation format (an oral or a poster presentation), topic, and date. Providing students with these choices shifts the balance of power towards the students, which may increase motivation and learner engagement in a learner-centred classroom (Weimer, 2002). Additionally, providing multiple means of expression, namely the choice to present an oral or a poster presentation, is one step towards achieving UDL (Rose \& Meyer, 2002), and allows

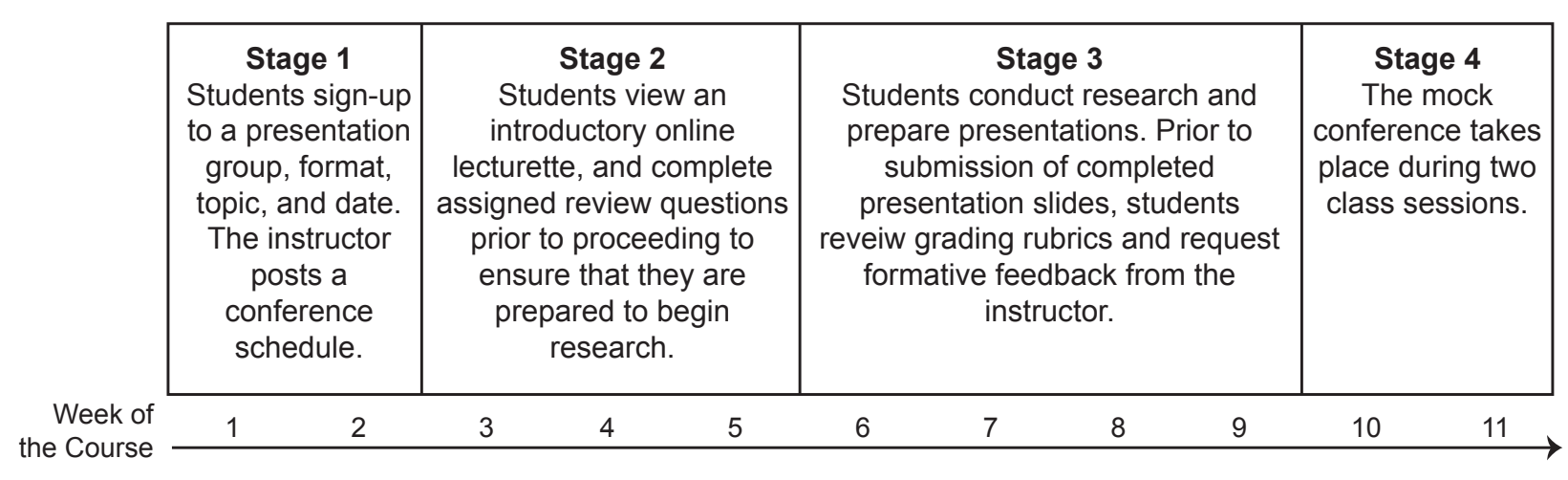

\section{FIGURE 1 \\ Mock Conference Model: Four Stages}


students to set an appropriate and motivating level of challenge for themselves. Indeed, some student groups indicated that they chose the presentation format that they felt would be maximally challenging (e.g., students for whom English is their second language have opted to deliver an oral presentation for this reason), while others chose the presentation format that presents challenges that they were most comfortable with.

Once students formed presentation groups and chosen topics, I post a conference schedule in which student presentations are organized into symposia. Students then begin stage two of the preparation process, and become acquainted with the conference theme. I provide students with resources via the course webpage to assist them with this, including an introductory lecturette (a short introductory talk) that introduces the theme, review questions to assess understanding of the lecturette, and a discussion board forum devoted to discussion of the lecturette and review questions. I do not provide an answer key for the review questions, and instead monitor the discussion board forum and play a guiding role as needed to assist students during this stage. This approach is intended to help students to develop selfdirected and active learning skills where the instructor acts as a learning guide, and is aligned with several key elements of Weimer's (2002) articulation of learnercentred teaching, including dual function of content and enhanced student responsibility for learning. Some of my students have expressed discomfort with this approach, perhaps due to more experience with traditional teacher-centred approaches (Candy, 1991; Felder \& Brent, 1996; Weimer, 2002).

During stage three, students research their topic and prepare their presentations. Several resources are provided to assist students with this stage, including a document with presentation requirements and rubrics, sample oral and poster presentations (based on the same topic to highlight differences in presentation formats; the oral presentation is provided in video format while the poster presentation is a PowerPoint slide), and a video tutorial pertaining to technical aspects of presentation preparation. Providing students with a variety of types of resources to access during this stage is intended to achieve multiple means of representation, as emphasized in the UDL framework (Rose \& Meyer, 2002).

Students are encouraged to review grading rubrics for the presentation slides as a final checkpoint prior to submitting completed slides, and to request formative feedback from the instructor during this stage. These activities may help to achieve a purpose and process of evaluation that is aligned with learnercentred teaching, in which the value of formative feedback and self-assessment is emphasized (Weimer, 2002). Final presentation slides are submitted 48 hours prior to the relevant conference class session. This allows me to preview the slides for content, post compilations of student presentation slides on the course webpage for the class to preview, and help shape closing remarks that I will deliver following student presentations by allowing me to identify potential gaps and/or inaccuracies in student presentations.

\section{Conference day activities}

During conference class sessions, I act as keynote speaker (reminding students of key lecturette concepts), symposium chair, and deliver closing remarks. The students act as presenters, audience members during presentations by their classmates, and participants in small group and whole class discussions. During the presentations, students take notes in an 'abstract book' that I prepare which is intended to serve as a note-taking aid. Each page of the abstract book includes questions to seek answers to during each individual presentation, highlighting key concepts to take away from each topic. To commence poster presentation symposia, individual representatives from each poster presentation group address the audience in succession to introduce their poster. A virtual poster viewing session then proceeds where students view posters from the course webpage with their laptops or from a letter-sized printed copy that they have brought to the class, and additional interaction between presenters and audience members occurs via the online discussion board. Post-presentation discussion initiated by students has typically pertained to personal or work-related experiences with the topic, suggesting that students value and are motivated by a conference theme that 
is relevant to real-life scenarios.

Following the presentations, students form small groups and are assigned questions to discuss, aimed at identifying key concepts from the presentations. Students are encouraged to compare notes in their abstract books as they discuss the questions. I then deliver closing remarks to reiterate key concepts, soliciting participation from the students to share thoughts arising from the small group discussions. This is also an opportunity for me to clarify concepts presented by students and/or to discuss important information that was omitted from student presentations.

\section{Post-conference activities}

Following the conference, students finish filling in their abstract books and answering review questions. They may use the online discussion board forum to compare notes and to continue poster presentation discussion. I monitor the discussion board, and join the conversation if I see that students are struggling.

\section{Customization of the Model}

This conference model is highly adaptable, and may be implemented across various disciplines and levels of an undergraduate program. In particular, the resources provided to students, conference day organization, presentation format, and instructor and student roles may be customized. For example, tasks assigned to the instructor including organizing conference symposia, chairing the symposia, and delivery of opening and closing remarks may be assigned to the students themselves, thus transferring more 'ownership' of the conference to the students. The specific mock conference described in this essay was implemented in a class of nursing students and the conference theme was chosen accordingly. Should this model be implemented in a course in which there may be a variety of student career goals and interests, the conference theme may be chosen in consultation with the students, to ensure that it is a theme that the class will be motivated to learn. The virtual poster presentation session described in this model was developed for use in a 'laptop university' where all students are provided with laptop computers and internet access is available in all classrooms. Should a virtual poster session not be possible in a particular classroom setting, this aspect of the conference may occur outside of class time or printed posters may be presented if possible.

\section{Final Comments}

Within this conference model, the instructor assumes the role of learning guide, while students play a more dominant role in presenting, discussing, and analyzing the content. A shift in the role of the instructor "from sage on the stage to guide on the side" (King, 1993) often requires instructors to carry out more design work and model effective learning practices (Weimer, 2002). In this conference model, there is considerable design work required in development of supplementary resources to guide students along a pathway towards self-directed learning of their presentation topic and preparation of their presentation. Additionally, students may initially resist an instructional method which requires active learning and self-directed learning, and in which the balance of power is shared by the students and instructor. However, empowering students to take control of their own learning and to take centre stage in the class may ultimately be a rewarding experience for the students (who learn not only the content, but also learning skills that will assist them in becoming lifelong learners) and instructor (who promotes learning, rather than focusing on teaching, in the classroom). Future work with this model will include additional evaluation of its effectiveness, by soliciting additional student feedback and suggestions based on their experiences as mock conference audience members and presenters.

\section{References}

Alsardary, S. \& Blumberg, P. (2009). Interactive, learner-centered methods of teaching mathematics. PRIMUS, 19, 401-416. 
Bransford, J.D., Brown, A.L., \& Cocking, R.R. (1999). How people learn: Brain, mind, experience, and school. Washington, DC: National Academy Press.

Candy, P.C. (1991). Self-direction for lifelong learning. San Francisco, CA: Jossey-Bass.

Felder, R.M., \& Brent, R. (1996). Navigating the bumpy road to student-centered instruction. College Teaching, 44, 43-47.

King, A. (1993). From sage on the stage to guide on the side. College Teaching, 41, 30-35.

Kramer, P., Ideishi, R.I., Kearny, P.J., Cohen, M.E., Ames, J.O., Shea, G.B, ... Blumberg, P. (2007). Achieving curricular themes through learner-centered teaching. Occupational Therapy in Health Care, 21(1/2), 185-198.

McGlynn, A.P. (2007). Teaching today's collegestudents: Widening the circle of success. Madison, WI: Atwood Publishing.

Orr, A.C., \& Hammig, S.B. (2009). Inclusive postsecondary strategies for teaching students with learning disabilities: A review of the literature. Learning Disability Quarterly, 32, 181-196.

Pliner, S.M. \& Johnson, J.R. (2004). Historical, theoretical, and foundational principles of universal instructional design in higher education. Equity \& Excellence in Education, 37, 105-113.

Rose, D. \& Meyer, A. (2002). Teaching every student in the digital age: Universal design for learning. Alexandria, VA: ASCD.

Salinas, M.F., Kane-Johnson, S.E., \& VasilMiller, M.A. (2008). Long-term learning, achievement tests, and learner centered instruction. Journal of the Scholarship of Teaching and Learning, 8, 20-28.
Schiller, S. Z. (2009). Practicing learner-centered teaching: Pedagogical design and assessment of a second life project. Journal of Information Systems Education, 20, 369-381.

Scott, S.S., McGuire, J.M., \& Foley, T.E. (2003). Universal design for instruction: A framework for anticipating and responding to disability and other diverse learning needs in the college classroom. Equity \& Excellence in Education, 36, 40-49.

Taylor, J. \& House, B. (2010). An exploration of identity, motivations and concerns of non-traditional students at different stages of higher education. Psychology Teaching Reviews, 16, 46-57.

Weimer, M. (2002). Learner-centered teaching: Five key changes to practice. San Francisco, CA: Jossey-Bass.

Zeff, R. (2007). Universal design across the curriculum. New Directions for Higher Education, 137, 27-44.

\section{Biography}

Kari Kumar is a Lecturer at the University of Ontario Institute of Technology, where she teaches within the Faculty of Health Sciences. 